\title{
Polymer Blends of PA6 and PPE Compatibilized by Poly[methylene(phenylene isocyanate)] (PMPI) Coupler
}

\author{
CHIH-RONG CHIANG, MING-YIH JU, and FENG-CHIH CHANG*
}

\author{
Institute of Applied Chemistry \\ National Chiao-Tung University \\ Hsinchu, Taiwan, Republic of China
}

\begin{abstract}
An oligomeric isocyanate, poly[methylene(phenylene isocyanate)] (PMPI), is demonstrated to be an efficient reactive compatibilizer for blends of polyamide- 6 (PA6) and poly(2,6-dimethyl-1, 4-phenylene ether)(PPE). Use of this compatibilizer results in substantial improvements in mechanical properties. The multiple functional isocyanate acts as a coupling agent and reacts with PA6 and PPE endgroups during melt processing to produce a PA6-co-PMPI-co-PPE mixed copolymer at the interface. This in situ-formed copolymer tends to reside at the interface to reduce the melt interfacial tension and enhance interface adhesion.
\end{abstract}

\section{INTRODUCTION}

$\mathrm{P}$ oly(2,6-dimethyl -1,4-phenylene ether)(PPE) is an amorphous polymer with high glass transition temperature $\left(215^{\circ} \mathrm{C}\right)$ and good ductility, but it lacks adequate melt processability and possesses poor solvent resistance. On the other hand, polyamide (PA6) shows good processibility as well as good chemical resistance. The combination of PPE and PA6 has a chance to give mutually complementary properties. However, simple melt blending of PA6 and PPE generally results in poor mechanical properties because of the lack of adequate interfacial adhesion.

More commonly, compatibility can be improved through copolymers with functional groups capable of specific interactions and/or chemical reactions with the blend components. Compatibility may also be enhanced through the addition of low molecular weight compounds promoting copolymer formation and/or crosslinking (1-3). A conventional $\mathrm{C}-\mathrm{X}$ reactive compatibilizer in a binary A/B blend system has the nonreactive $C$ segment structurally identical or miscible with component $\mathrm{A}$ and the reactive $\mathrm{X}$ groups that are capable of a chemical reaction with component $B$ of the blend to form in situ the C-X-B graft or block copolymer during melt processing. Literature reviews on the area of PA/PPE blends compatibilized by modified PPE (4-10) or styrenic copolymers with reactive functional groups (11-15) had been made in our previous papers (16-18).

If both blend components (A and $B$ ) contain the functional groups that can react with the reactive

To whom correspondence should be addressed. compatibilizer with comparable rate, formation of certain amount of copolymers containing segments of A and $B$ components is expected. The in situ-formed mixed copolymer anchoring along the interface is more effective than the conventional compatibilizer in compatibilizing a blend. However, the presence of the C segment to be miscible (or structurally identical) with component $\mathrm{A}$ for a conventional reactive $\mathrm{C}-\mathrm{X}$ compatibilizer may not be necessary or may even be undesirable. The lower compatibility between $C$ segment of C-X compatibilizer with blend constituents A and $B$ is even more desirable because the $C-X$ coupler prefers to reside at the interface and has a better opportunity to contact and react with both $\mathrm{A}$ and $\mathrm{B}$ components simultaneously.

The coupling approach in polymers has been briefly reviewed by Xanthos (1). Brown (19) and Liu (20). The basic criterion for such a coupling approach applying in polymer blends as reactive compatibilizer is that both blend constituents must possess certain necessary functional groups capable of bond reacting with the coupler during melt processing to form various mixed copolymers with segments containing both blend components. Tzur et al. (21) reported that the compatibilization of polypropylene/copolyamide $6 / 6,9$ blend can be achieved by peroxide decomposition in the molten blend in the presence of a triallyl cyanurate through reactive blending process. Teh and Rudin (22) reported that the direct grafting of polystyrene onto polyethylene can be carrier out in a twin screw extruder with an organic peroxide (dicumyl peroxide, DP) and a coupling coagent (triallyl isocyanurate, TAIC). The extruded blends exhibited enhancement in impact properties at an optimum level of peroxide and coupling coagent. The synthesized difunctional unsat- 
Table 1. Processing Conditions.

\begin{tabular}{|c|c|c|c|c|c|c|c|c|c|c|c|c|}
\hline \multicolumn{13}{|c|}{ A. Extrusion Condition } \\
\hline \multicolumn{2}{|c|}{ Composition } & \multirow{3}{*}{ Stage: } & \multicolumn{10}{|c|}{ Barrel Temperature $\left({ }^{\circ} \mathrm{C}\right)$} \\
\hline PA6 & PPO & & 1 & 2 & 3 & 4 & 5 & 6 & 7 & 8 & 9 & Die \\
\hline $\begin{array}{l}70 \\
50 \\
30\end{array}$ & $\begin{array}{l}30 \\
50 \\
70\end{array}$ & & $\begin{array}{l}210 \\
210 \\
210\end{array}$ & $\begin{array}{l}260 \\
260 \\
270\end{array}$ & $\begin{array}{l}270 \\
270 \\
280\end{array}$ & $\begin{array}{l}285 \\
290 \\
290\end{array}$ & $\begin{array}{l}280 \\
280 \\
290\end{array}$ & $\begin{array}{l}275 \\
280 \\
285\end{array}$ & $\begin{array}{l}270 \\
280 \\
285\end{array}$ & $\begin{array}{l}270 \\
280 \\
285\end{array}$ & $\begin{array}{l}270 \\
280 \\
285\end{array}$ & $\begin{array}{l}270 \\
285 \\
285\end{array}$ \\
\hline
\end{tabular}

Screw speed: $260 \mathrm{rpm}$

Feeding rate: $125 \mathrm{~g} / \mathrm{min}$

\section{B. Injection Condition}

\begin{tabular}{|c|c|c|c|c|c|c|c|}
\hline \multicolumn{2}{|c|}{ Composition } & \multirow[b]{2}{*}{ Stage: } & \multicolumn{4}{|c|}{ Barrel Temperature $\left({ }^{\circ} \mathrm{C}\right)$} & \multirow[b]{2}{*}{ Mold Temp. $\left({ }^{\circ} \mathrm{C}\right)$} \\
\hline PA6 & PPO & & 1 & 2 & 3 & Nozzle & \\
\hline $\begin{array}{l}70 \\
50 \\
30\end{array}$ & $\begin{array}{l}30^{\mathrm{a}} \\
50^{\mathrm{a}} \\
70^{\mathrm{b}}\end{array}$ & & $\begin{array}{l}250 \\
260 \\
290\end{array}$ & $\begin{array}{l}260 \\
275 \\
305\end{array}$ & $\begin{array}{l}270 \\
290 \\
310\end{array}$ & $\begin{array}{l}280 \\
300 \\
310\end{array}$ & $\begin{array}{r}80 \\
100 \\
100\end{array}$ \\
\hline
\end{tabular}

a: Molded by Arturg injection molding machine
b: Molded by Toshiba injection molding machine.

urated-isocyanate compounds used as sizing agents on carbon fibers substantially improve fiber/acrylicmatrix bonding and mechanical properties that was reported by Thomas et al. (23).

Koseki et al. (24) demonstrated that poly(ethylene terephthalate)(PET) film coated with PPE can be compatibilized by methylene diisocyanate (MDI) as a coupling agent and resulted in substantial improvement of chemical and heat resistance. Pernice et al. (25) claimed that the impact modified PA/PPE blend containing 0.5 to $3.0 \mathrm{wt} \%$ of an organic diisocyanate such as 4,4'-(diphenyl methane) diisocyanate or 2,4-toluene diisocyanate has a good balance of mechanical, thermal and processing properties. Koning et al. (26) reported that PPE-nylon copolymers synthesized by reaction of PPE, polyamide and lactam-blocked diisocyanate can act as effective compatibilizers for nylon/ PPE blends. The poly(methylene (phenylene isocyanate)(PMPI) is able to act as an efficient coupling agent for blends of polyphenylene sulfide (PPS) and PPE by improving impact strength and processability (27-29). Several blend systems such as polyester/ polyester (30), polyester/polyamide (31), polyester/ PPE (32), and polyamide/PPE $(17,33)$ were effectively compatibilized by a multifunctional epoxy resin as a coupler type reactive compatibilizer.

In a series of continuous studies on the compatibilized PA6/PPE blends, this paper will report another example that a commercially available oligomeric isocyanate, PMPI, is able to effectively compatibilize PA6/PPE blends by functioning as a coupling agent. In addition, their specific compatibility and correlation with their mechanical properties will be discussed in details.

\section{EXPERIMENTAL}

\section{Materials}

The unmodified poly (2,6-dimethyl-1, 4-phenylene ether)(PPE) powder used in this study, obtained from
General Electric Plastics, had an intrinsic viscosity of $0.4 \mathrm{dl} / \mathrm{g}$ measured in chloroform at $25^{\circ} \mathrm{C}$. The polyamide- 6 (PA6) employed is a commercial grade Novamide 1010C2 supplied by the Mitsubishi Kasei Co. Ltd. of Japan. The reactive coupling compatibilizer, poly (methylene(phenylene isocyanate))(PMPI) containing $31.5 \%$ NCO group was obtained from BASF Chemical Co. This coupler type reactive compatibilizer has a melt viscosity of $200 \mathrm{cps}$ measured at $25^{\circ} \mathrm{C}$ and has the average functional groups per chain of 2.7 as shown in Scheme 1.

\section{Blend Preparation}

All blends were prepared on a co-rotating $30 \mathrm{~mm}$ twin-screw extruder $(\mathrm{L} / \mathrm{D}=36$, Sino-Alloy Machinery Inc. of Taiwan) with a decompression zone. The rotating speed of screw was controlled at $260 \mathrm{rpm}$. The barrel temperatures were set from 210 to $290^{\circ} \mathrm{C}$. The standard ASTM 1/8 inch testing specimens were prepared by an Arburg 3-oz injection molding machine. The temperatures of injection molding were adjusted for optimizing the processing conditions depending on the compositions. The detailed processing conditions for the extrusion and injection molding are listed in Table 1.

\section{Solvent Extraction}

Several solvent extraction techniques (5, 34-37) have been reported to give successful separation of the components of immiscible polymer blends. In order to isolate and identify the in situ-formed PA6-coPMPI-co-PPE copolymer during melt blending, complicated solvent extractions have been carried out. Two grams of powder of the compatibilized blend was immersed and agitated in $50 \mathrm{ml}$ toluene for 24 hours. The resultant suspended mixture was separated by centrifugation at $13,000 \mathrm{rpm}$ for 50 minutes. The clear upper solution containing PPE, PMPI and PMPI- 


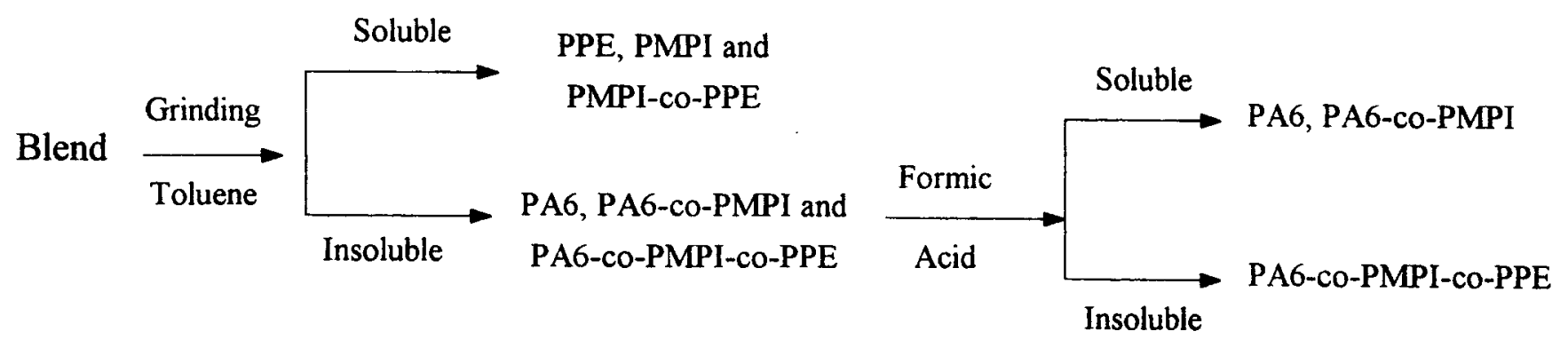

Scheme II. Solvent extraction procedures.

co-PPE was collected by a pipette. The bottom undissolved solid was re-extracted by the same procedures for at least five times to assure complete removal of PPE, PMPI, and PMPI-co-PPE from the compatibilized blend. After repeated extractions by toluene, the solid residue was dried in an oven to remove the toluene solvent. The residue was then extracted with excess of formic acid at ambient condition for 12 hours to remove free PA6 and PA6-co-PMPI from the residue. The suspended mixture was poured into a separatory funnel and settled for 24 hours. The clear bottom phase containing PA6 and PA6-co-PMPI was removed. The white top layer was collected into a beaker for next formic acid extraction. Similar formic acid extraction was repeated at least five times. The upper white and undissolved layer containing mostly the PA6-co-PMPIco-PPE copolymer was rinsed with di-ion water and dried in an oven. In order to ensure that all the remaining PPE, PMPI, and PMPI-co-PPE have been removed, the dried residue was extracted again by toluene and chloroform in sequence. Scheme II illustrates the extraction procedures.

\section{Characterizations}

In order to characterize the in situ-formed PA6-coPMPI-co-PPE copolymer, Fourier transform infrared spectroscopic (FT-IR) analyses were carried out using a Nicolet 500 Infrared Spectrophotometer.

To verify the reaction of PPE (or PA6) with PMPI based on viscosity increase, torque versus time measurements were carried out in a Brabender PlastiCorder Mixer at $290^{\circ} \mathrm{C}$ and $30 \mathrm{rpm}$. Melt flow rates (MFRs) of the blends were also measured at $290^{\circ} \mathrm{C}$ using various loads depending on the composition of the PA6/PPE blends. Capillary rheological measurements of the blends were carried out at $290^{\circ} \mathrm{C}$ using a Kayeness Galaxy Capillary Rheometer with a die orifice radius of 0.04 inch and $L / D$ of 20 .

The morphologies of the injection molded specimens were examined using a Hitachi S-570 scanning electron microscope (SEM) at an accelerating voltage of $20 \mathrm{KV}$. The cryogenically fractured surfaces of the molded specimens were coated with thin film of gold to prevent charging.

Thermal properties of the sample were studied using a DSC analyzer from the Seiko Co. Heating and cooling rates were both controlled at $3^{\circ} \mathrm{C} / \mathrm{min}$ and
PA6

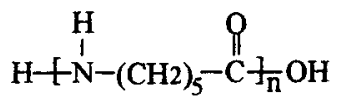

PPE

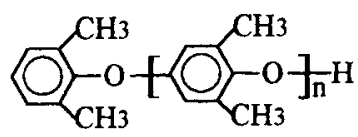

PMPI
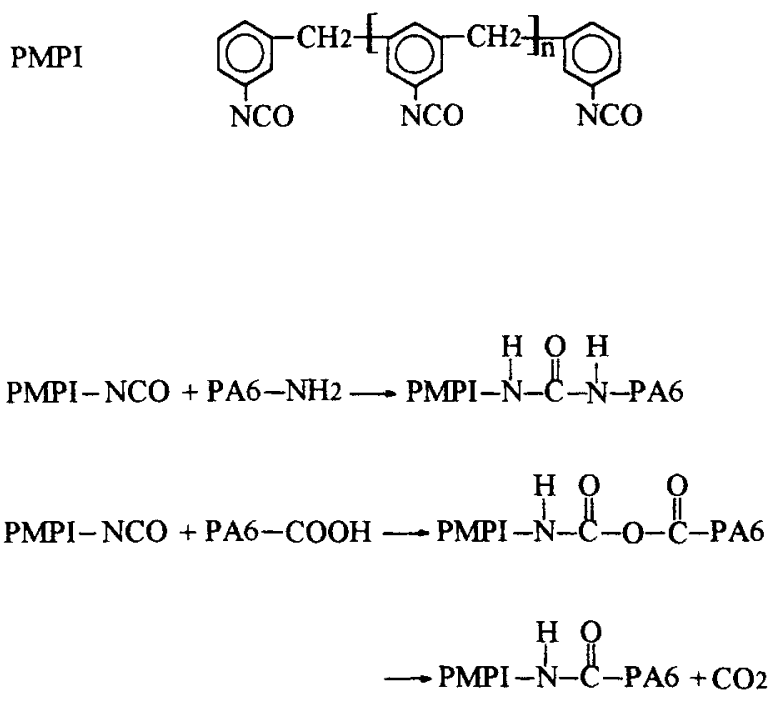

$\mathrm{PMPI}-\mathrm{NCO}+\mathrm{PPE}-\mathrm{OH} \rightarrow \mathrm{PMPI}-\mathrm{N}-\mathrm{C}-\mathrm{O}-\mathrm{PPE}$

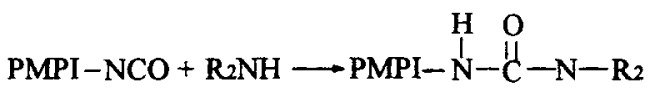

Scheme I. Chemical structures and related reactions.

measurements were made between 30 and $300^{\circ} \mathrm{C}$. The percent of PA6 crystallinity in the blend was measured on the basis of that the heat of fusion of PA6 at $100 \%$ crystalline state is $190.6 \mathrm{~J} / \mathrm{g}(34)$. 
Tensile tests were conducted at ambient conditions using an Instron Universal Testing Machine Model 4201 according to ASTM D638. The crosshead speed was $5 \mathrm{~mm} / \mathrm{min}$. Unnotched Izod impact strengths were performed at ambient conditions according to ASTM-D256 method. All injection molded specimens were conditioned in the laboratory atmosphere condition $\left(23-25^{\circ} \mathrm{C}\right.$ and $50-60 \%$ humidity) for a minimum of 7 days before testing. The critical strain energy release rate $(G c)$ was measured using the method derived by Plati and Williams (38). There were various crack lengths selected and notched radius was 0.005 inch.

\section{RESULTS AND DISCUSSION}

\section{Chemistry of the Coupler Type Reactive Compatibllization}

A low-molecular-weight multi-functional epoxy resin acting as coupling agent has been previously demonstrated as an excellent reactive compatibilizer for PA6/PPE blends (17), resulting in drastic improvements in mechanical properties. Portion of this multifunctional epoxy monomer is able to react in situ at the interface with $-\mathrm{NH}_{2}$ (and/or $-\mathrm{COOH}$ ) of PA6 and phenolic -OH of PPE simultaneously to form the mixed copolymers, PA6-co-Epoxy-co-PPE. This in situformed copolymer tends to anchor along the interface to function as an effective compatibilizer of the blend. This unconventional reactive compatibilizer through in situ coupling reaction can be applied to many blend systems provided that both blend constituents contain the necessary functional groups capable of reacting with the coupler. Similarly, the -NCO groups of this oligomeric isocyanate (PMPI) can also react simultaneously with $-\mathrm{NH}_{2}$ or $-\mathrm{COOH}$ end group of PA6 and -OH end group of PPE to form the desired PA6-coPMPI-co-PPE copolymer. The structures of these components and the proposed reactions are shown in Scheme I. Certainly we do not expect that all the added PMPI can react with both blend components simultaneously. Portion of the added PMPI may react with only one particular blend component as a chain extender or chain brancher, and such product is unable to function as a compatibilizer. The efficiency of compatibilization by this coupler depends on how many of the mixed copolymers can be produced. Many factors influence how efficiently this copolymer can be produced during melt blending such as relative reactivity and relative compatibility between the coupler and the blend constituents $A$ and $B$, and the melt sequence of $\mathrm{A}$ and $\mathrm{B}$. It is more preferable that the coupler is incompatible with both blend components; the coupler tends to reside at the interface and has better opportunity to contact and react with both components simultaneously. If the coupler is more compatible with one particular phase, it may react completely with that phase especially when this particular phase has higher reactivity and melts at lower temperature. The formation of the PA6-co-PMPI-co-
PPE is critical for this coupler to be considered as a reactive compatibilizer.

In order to prove this mixed copolymer is indeed produced during melt blending, complicated extractions of the compatibilized blend to isolate and identify this copolymer were carried out as shown in Scheme 1. For the uncompatibilized PA6/PPE $=30 / 70$ blend, no PPE was found in the final formic acid insoluble residue. A similar result was previously reported by Chambell et al. (5).

The in situ reactions among PA6, PMPI and PPE during melt mixing may form PA6-co-PMPI-co-PPE copolymer that is soluble neither in toluene nor in formic acid. The reactively compatibilized PA6/PPE/ PMPI $=30 / 70 / 1$ blend may contain the following species: PA6, PA-co-PMPI, PMPI, PMPI-co-PPE, PPE and PA6-co-PMPI-co-PPE. We found that the melt blended mixture of PPE/PMPI $=50 / 1$ was completely dissolved in toluene and the melt blended PA6/PMPI $=50 / 1$ was also soluble in formic acid. Therefore, toluene can dissolve free PPE, free PMPI and PPE-coPMPI while formic acid is able to dissolve free PA6, free PMPI, and PA6-co-PMPI. In other words, the copolymer PA6-co-PMPI-co-PPE is the only species expected to be insoluble on both solvents. The insoluble residue after repeated extractions by toluene and formic acid can be assumed to be the mixed copolymer but requires further identification.

Figure 1 shows FT-IR spectra of neat PA6, PPE and PMPI, respectively. Figure 1(a) shows the characteristic absorption bands of the pure PA6 at 1640, 1546 and $1415 \mathrm{~cm}^{-1}$, corresponding to the carbonyl stretching $\left(v_{\mathrm{c}=\mathrm{o}}\right), \mathrm{N}-\mathrm{H}$ bending $\left(v_{\mathrm{N}-\mathrm{H}}\right)$ and $\mathrm{CH}_{2}$ bending, respectively. PPE shows two characteristic bands of the ether at 1023 and $1190 \mathrm{~cm}^{-1}$, corresponding to the C-O stretch as shown in Fig. 1(b). The ring stretching of PPE gives the band at $1610 \mathrm{~cm}^{-1}$. Figure 1 (c) shows that the NCO stretching of PMPI gives a broad and intense absorption band at $2270 \mathrm{~cm}^{-1}$. The ring stretching of PMPI occurs at the absorption band of 1609 $\mathrm{cm}^{-1}$. The FT-IR spectrum of the insoluble residue, assumed to be the PA6-co-PMPI-co-PPE copolymer, is shown in Fig. 2. Comparing Fig. 2 with the spectra of Figs. $I(a)$ to $I(c)$, this undissolved residue gives the characteristic bands of the PA6 segment, carbonyl stretching at $1639 \mathrm{~cm}^{-1}$ and $\mathrm{N}-\mathrm{H}$ bending at 1544 $\mathrm{cm}^{-1}$, respectively. Figure 2 also possesses the PPE $\mathrm{C}-\mathrm{O}$ stretching of the phenylene ether at 1022 and $1191 \mathrm{~cm}^{-1}$. The ring stretching of PPE segments at $1610 \mathrm{~cm}^{-1}$ is overlapping with the carbonyl absorption band of PA6 segments at $1638 \mathrm{~cm}^{-1}$. The characteristic NCO band of the pure PMPI cannot be detected from the spectrum of this undissolved solid residue probably because of the small quantity or because it is consumed in reaction. Based on above discussion, the formation of the desirable PA6-co-PMPI-co-PPE copolymer during melt blending has been positively identified. The weight fraction of the undissolved residue was approximately $2 \%$ of the original compatibilized blend. Based on theoretical calculation, only 


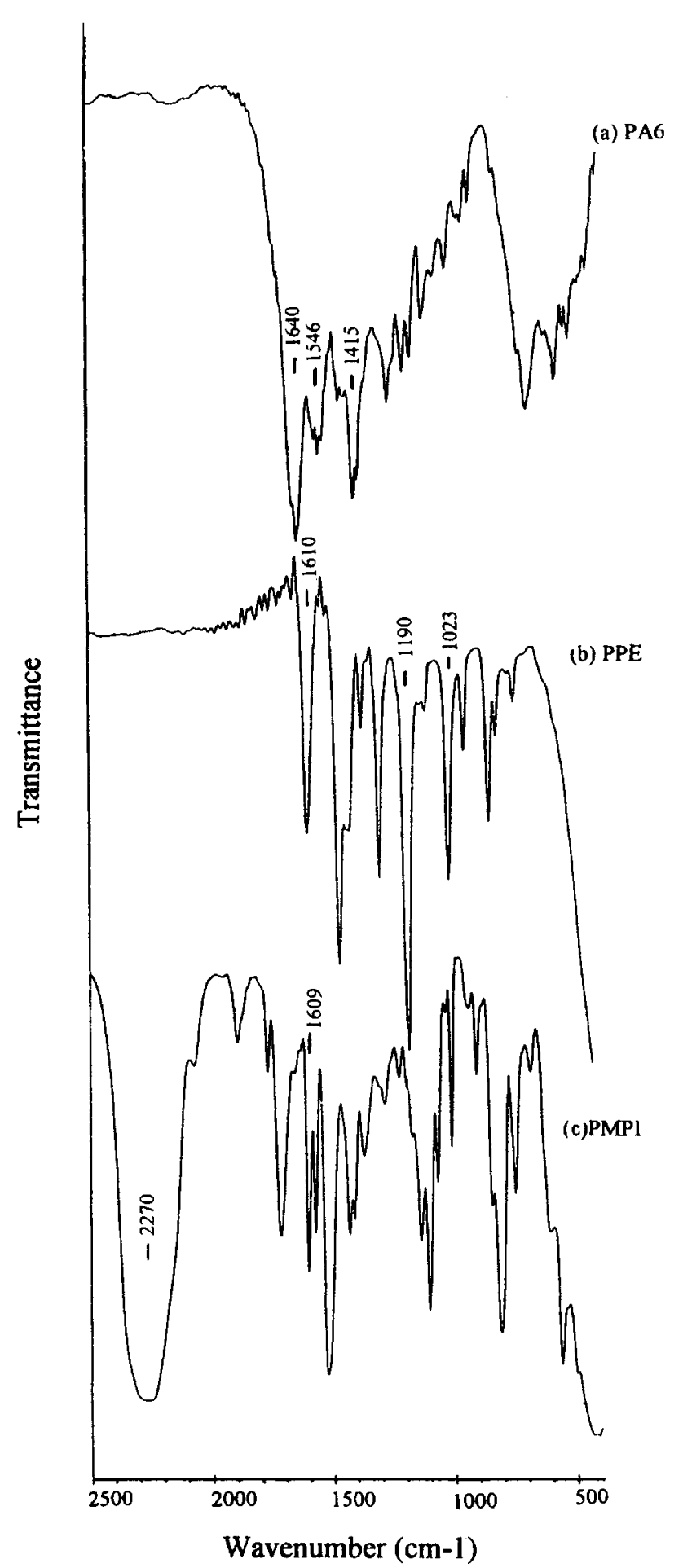

Fig. 1. Infrared spectra of neat components, (a) PA6, (b) PPE and (c) PMPI.

small fraction of the added PMPI resulting the desired PA6-co-PMPI-co-PPE copolymer. The rest of the added PMPI was either unreacted or consumed in reacting with one blend component to form PMPI-co-PA6 and PMPI-co-PPE.

It was reported that the secondary amine is attached via the amino nitrogen to the PPE methyl

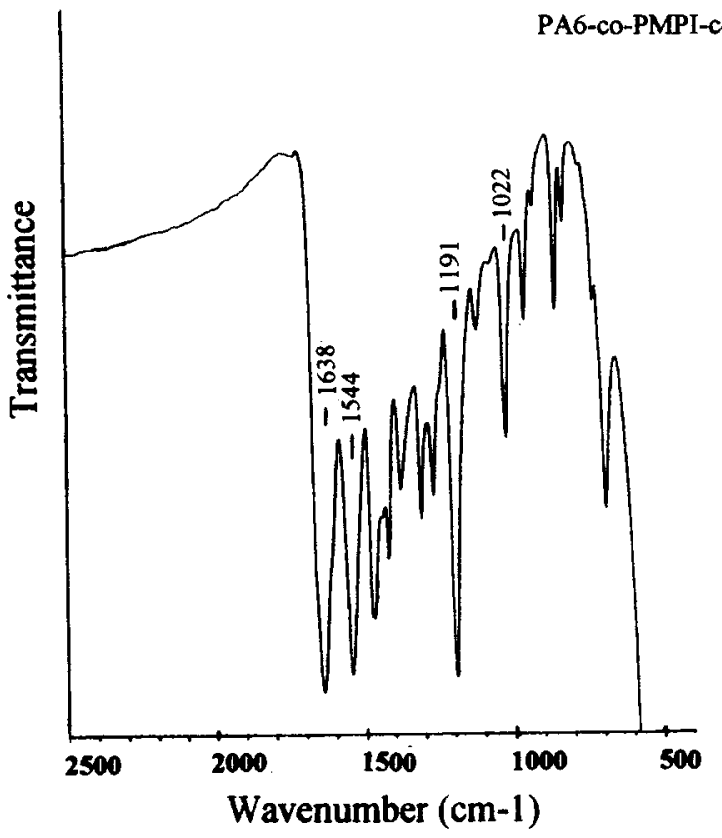

Fig. 2. Infrared spectrum of the extracted residue.

group at the head end of the polymer chain (39). This secondary amine can be released after the PPE is heated at high temperature. Portion of the added PMPI may be consumed in reacting with the released secondary amine (Scheme I). Kinetically this small secondary amine molecule will react with PMPI faster if it is not vaporized during melt blending.

Table 2 gives the estimated numbers of functional groups from the compatibilizer and blend components. At 1 phr PMPI concentration, the functional numbers of $-\mathrm{NCO}$ from PMPI is about $61-71 \%$ of the total functional groups from PA6 + PPE + secondary amine. Based on above estimated data, formation of the desirable PA6-co-PMPI-co-PPE copolymer is highly possible. At 0.1 phr PMPI concentration, the functional group ratio is less than $10 \%$, the chance of producing the mixed copolymer is significantly less.

\section{Extruder Current}

The extruder currents were obtained here to compare relative viscosities of uncompatibilized and compatibilized blends. Relatively a better compatibilized blend usually results in higher viscosity than the uncompatibilized counterpart. The presence of PMPI causes viscosity increase essentially on all PA6/PPE blends investigated as indicated by the recorded higher extruder current (Table 3). The presence of PMPI coupling agent increases the viscosity of compatibilized blends because of the expected molecular weight increase by chain extension and coupling reaction. Increase of interfacial friction by the PA-co-PMPI-coPPE copolymer anchoring along the interface may also contribute to the observed higher viscosity of the compatibilized blend. Relative to the uncompatibilized blend, the resultant slight viscosity increase of the 
Table 2. Functional Group Numbers of Compatibilized Blends.

\begin{tabular}{|c|c|c|c|c|}
\hline \multirow[b]{2}{*}{ PA6/PPE/PMPI } & \multicolumn{4}{|c|}{$\begin{array}{l}\text { Functional group equivalence } \\
\text { per } 10^{6} \mathrm{~g} \text { sample }\end{array}$} \\
\hline & PA6 $^{\mathbf{a}}$ & PPE & Secondary Amine ${ }^{c}$ & PMPI \\
\hline $\begin{array}{l}70 / 30 / 1.0 \\
70 / 30 / 0.5 \\
70 / 30 / 0.1\end{array}$ & $\begin{array}{l}82.3 \\
82.3 \\
82.3\end{array}$ & $\begin{array}{l}15.0 \\
15.0 \\
15.0\end{array}$ & $\begin{array}{l}15.0 \\
15.0 \\
15.0\end{array}$ & $\begin{array}{r}75.0 \\
37.5 \\
7.5\end{array}$ \\
\hline $\begin{array}{l}50 / 50 / 1.0 \\
50 / 50 / 0.5 \\
50 / 50 / 0.1\end{array}$ & $\begin{array}{l}58.8 \\
58.8 \\
58.8\end{array}$ & $\begin{array}{l}25.0 \\
25.0 \\
25.0\end{array}$ & $\begin{array}{l}25.0 \\
25.0 \\
25.0\end{array}$ & $\begin{array}{r}75.0 \\
37.5 \\
7.5\end{array}$ \\
\hline $\begin{array}{l}30 / 70 / 1.0 \\
30 / 70 / 0.5 \\
30 / 70 / 0.1\end{array}$ & $\begin{array}{l}35.3 \\
35.3 \\
35.3\end{array}$ & $\begin{array}{l}35.0 \\
35.0 \\
35.0\end{array}$ & $\begin{array}{l}35.0 \\
35.0 \\
35.0\end{array}$ & $\begin{array}{r}75.0 \\
37.5 \\
7.5\end{array}$ \\
\hline
\end{tabular}

compatibilized blend did not encounter any noticeable viscosity-induced processing problem.

\section{Torque Versus Time}

Torque measurements have been used successfully to obtain qualitative information concerning the chemical reactivity and the extent of reaction in a reactively compatibilized blend (35). Figure 3 illustrates the torque versus time curves at $290^{\circ} \mathrm{C}$ for PA6, PPE, PA6 $/$ PMPI $=50 / 1$, and PPE $/$ PMPI $=50 / 1$ mixtures. The torque of the virginal PA6 is very low and remains almost constant at this temperature. The torque value of the neat PPE is very high but decreases gradually after 100 seconds probably because of thermal degradation. PPE tends to crosslinks at high temperature but the data obtained from this study did not result in the expected viscosity increase. The torques of the PA6/PMPI $=50 / 1$ and PPE $/ \mathrm{PMPI}=50 / 1$ mixtures are

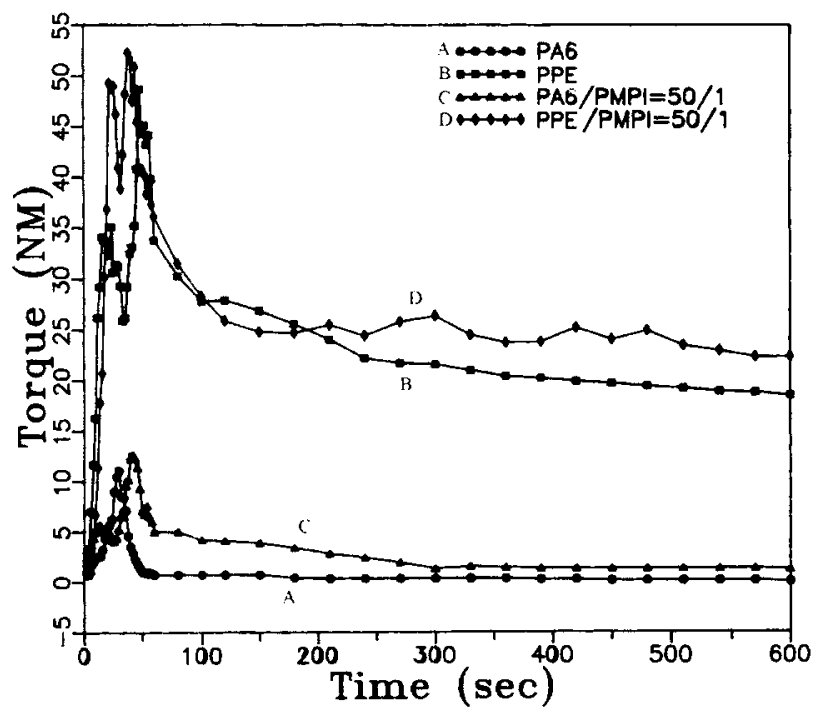

Fig. 3. Plots of torque versus time for PA6, PPE, PA6/PMPI = $50 / 1$, and $P P E / P M P I=50 / 1$ mixture.
Table 3. Extruder Current and Melt Flow Rate of the PA6/PPE Blends.

\begin{tabular}{|c|c|c|}
\hline Composition & $\begin{array}{l}\text { Extruder Current }{ }^{a} \\
\text { (Amp) }\end{array}$ & $\begin{array}{l}\text { Melt Flow Rate } \\
\text { (g/10 min) }\end{array}$ \\
\hline $\begin{array}{l}\mathrm{PA6} / \mathrm{PPE}=70 / 30 \\
\mathrm{PA6} / \mathrm{PPE} / \mathrm{PMPI}=70 / 30 / 0.1 \\
\mathrm{PA6} / \mathrm{PPE} / \mathrm{PMPI}=70 / 30 / 0.5 \\
\mathrm{PA6} / \mathrm{PPE} / \mathrm{PMPI}=70 / 30 / 1.0\end{array}$ & $\begin{array}{l}17.3-18.1 \\
18.4-19.3 \\
19.7-21.0 \\
25.6-25.9\end{array}$ & $\begin{array}{r}103.6^{b} \\
73.3^{b} \\
58.8^{b} \\
17.4^{b}\end{array}$ \\
\hline $\begin{array}{l}\mathrm{PA6} / \mathrm{PPE}=50 / 50 \\
\mathrm{PA6} / \mathrm{PPE} / \mathrm{PMPI}=50 / 50 / 0.1 \\
\mathrm{PA6} / \mathrm{PPE} / \mathrm{PMPI}=50 / 50 / 0.5 \\
\mathrm{PA6} / \mathrm{PPE} / \mathrm{PMPI}=50 / 50 / 1.0\end{array}$ & $\begin{array}{l}19.2-19.6 \\
21.2-21.6 \\
24.6-25.2 \\
28.9-29.3\end{array}$ & $\begin{array}{r}85.8^{c} \\
92.8^{c} \\
42.6^{c} \\
8.8^{c}\end{array}$ \\
\hline $\begin{array}{l}\mathrm{PA6} / \mathrm{PPE}=30 / 70 \\
\mathrm{PA6} / \mathrm{PPE} / \mathrm{PMPI}=30 / 70 / 0.1 \\
\mathrm{PA6} / \mathrm{PPE} / \mathrm{PMPI}=30 / 70 / 0.5 \\
\mathrm{PA6} / \mathrm{PPE} / \mathrm{PMPI}=30 / 70 / 1.0\end{array}$ & $\begin{array}{l}19.6-20.2 \\
19.9-21.6 \\
25.0-26.2 \\
34.8-36.2\end{array}$ & $\begin{array}{r}18.5^{\mathrm{d}} \\
17.9^{\mathrm{d}} \\
4.8^{\mathrm{d}} \\
1.9^{\mathrm{d}}\end{array}$ \\
\hline
\end{tabular}

- Screw speed: $260 \mathrm{rpm}$. Feeding rate: $125 \mathrm{~g} / \mathrm{min}$.

b $2.16 \mathrm{~kg}, 290^{\circ} \mathrm{C}$.

c $3.8 \mathrm{~kg}, 290^{\circ} \mathrm{C}$.

d $5.0 \mathrm{~kg}, 290^{\circ} \mathrm{C}$.

slightly higher than those of PA6 and PPE respectively. Plots of torque versus time for PA6, PPE, PA6/PPE = $50 / 50$, and PA6/PPE/PMPI $=50 / 50 / 1$ mixtures are given in Fig. 4. The PA6/PPE $=50 / 50$ blend shows the torque significantly lower than the average value of PA6 and PPE, only slightly higher than that of the PA6. This result is not unusual for blends with great viscosity difference. The compatibilized blend, PA6/ $\mathrm{PPE} / \mathrm{PMPI}=50 / 50 / 1$, shows a significantly higher torque than corresponding uncompatibilized PA6/PPE $=50 / 50$ blend, even higher than the viscous of the neat PPE and the PPE/PMPI $=50 / 1$ blend (Fig. 3). This result was quite surprising, and repeated experiments were carried out to positively confirm this unusual result. The observed unusual high viscosity of this PA6/PPE/PMPI $=50 / 50 / 1$ compatibilized blend is probably due to the enhancement of the interfacial friction for the PA6-co-PMPI-co-PPE copolymer anchoring along the interface.

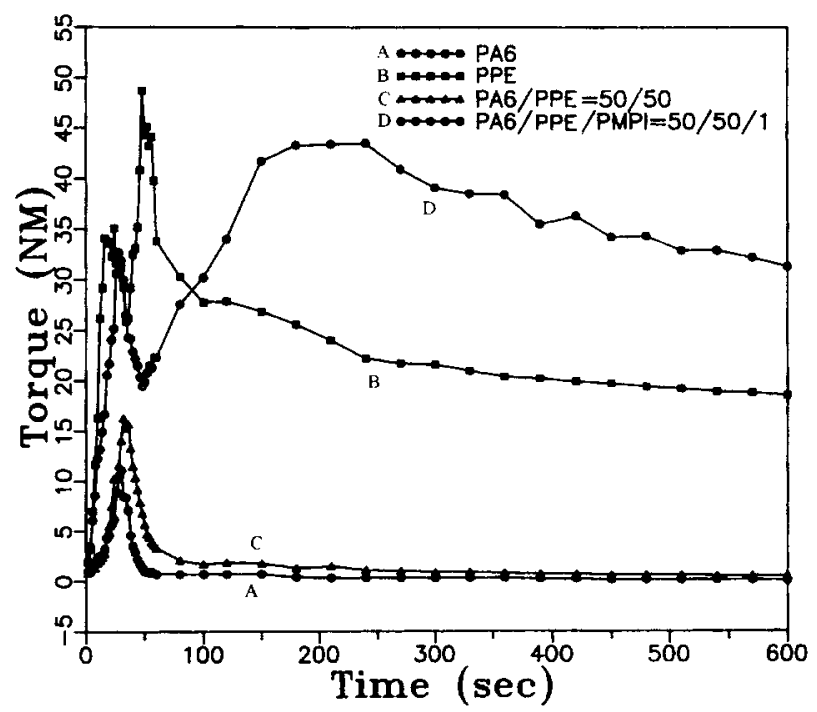

Fig. 4. Plots of torque versus time for PA6, PPE, PA6/PPE = 50/50, and PA6/PPE $/ P M P I=50 / 50 / 1$ mixture. 


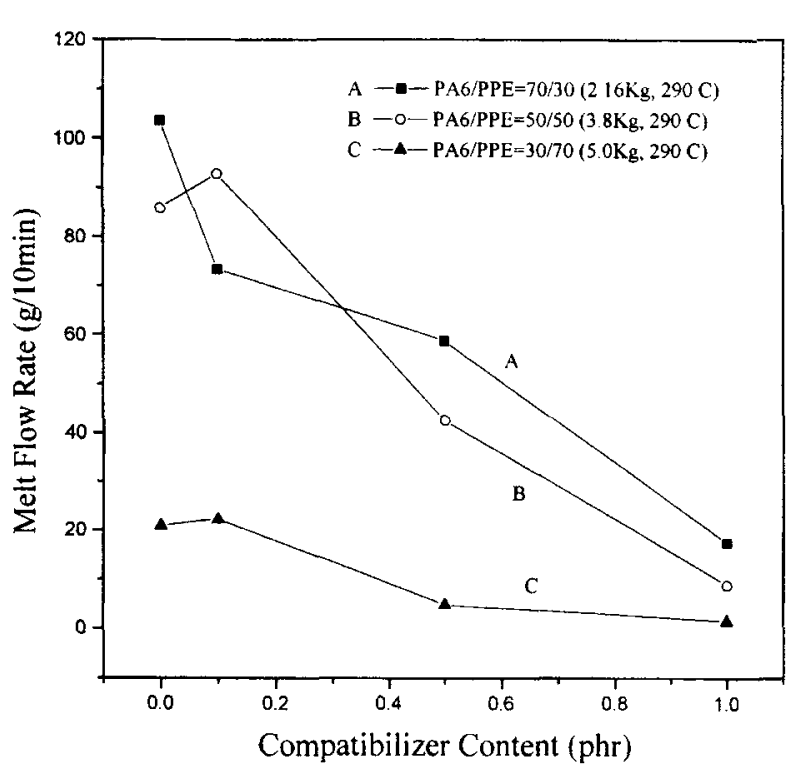

Fig. 5. Effect of compatibilizer quantity on the melt flow rate of the PA6/PPE blends.

\section{Melt Fow Rates}

The melt flow rates (MFRs) at $290^{\circ} \mathrm{C}$ of all the compatibilized and uncompatibilized blends in this study are summarized in Table 3 and Fig. 5. The load employed were varied depending on compositions of the PA6/PPE blends. Figure 5 clearly demonstrates that the presence of greater amounts of PMPI results in lower MFR values for all three blend series as would be expected. In addition to the expected molecular weight increase, the interfacial friction caused by in situ-formed copolymer anchoring along the interface may also partially contribute to the observed higher viscosity of these PMPI compatibilized blends.

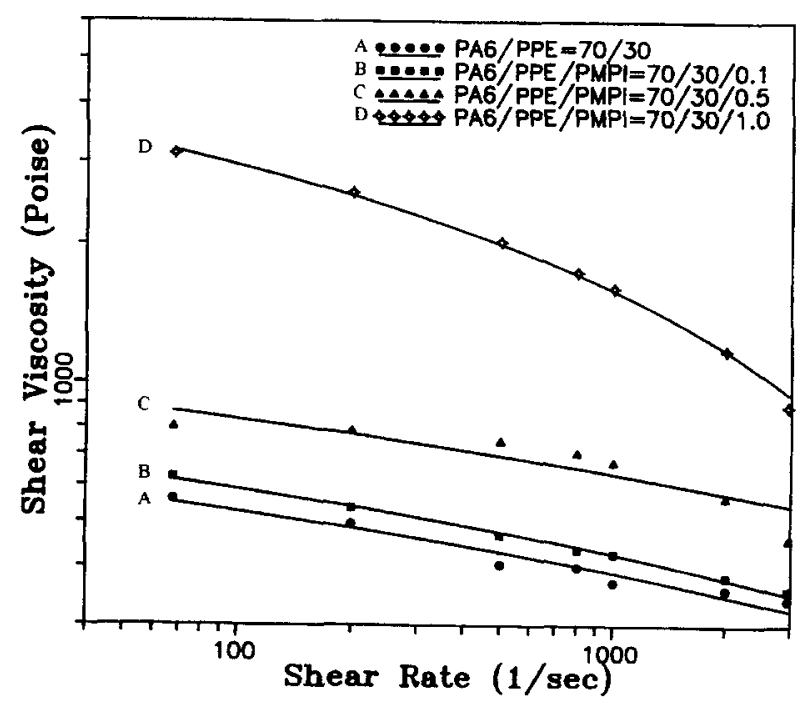

Fig. 6. Plots of shear viscosity versus shear rate for uncompatibilized and compatibilized PA6/PPE $=70 / 30$ blends.

\section{Capillary Rhoometry}

The apparent shear viscosity versus shear rate behaviors of uncompatibilized and compatibilized PA6/ $\mathrm{PPE}=70 / 30$ blends at $290^{\circ} \mathrm{C}$ are shown in Fig. 6 where the effect of PMPI compatibilizer on the apparent viscosity of this PA6-rich blend system is quite significant. The uncompatibilized blend has the expected lowest viscosity. The viscosity of this compatibilized PA6/PPE $=70 / 30$ blend series increases with the increase of the quantity of PMPI compatibilizer. The addition of $1.0 \mathrm{phr}$ of PMPI results in substantial viscosity rise. Higher viscosity from a better compatibilized blend can be related to the expected higher molecular weight from chain extension and coupling reaction. Effect of the PMPI compatibilizer on the rheological behavior of the PA6/PPE $=50 / 50$ blends is depicted in Fig. 7. Introduction of $0.1 \mathrm{phr}$ PMPI to the $\mathrm{PA6} / \mathrm{PPE}=50 / 50$ blend results in about the same viscosity as the uncompatibilized blend. The relatively small quantity of PMPI may mostly consumed in reacting with the released secondary amine and results in none or few copolymer formation. For those blends containing higher PMPI content ( 0.5 and $1 \mathrm{phr}$ ), greater numbers of copolymers are produced and result in substantial viscosity increase as would be expected. The trend of the rheological behavior of the PA6/PPE $=30 / 70$ blend series is similar to that of the PA6/ $\mathrm{PPE}=50 / 50$ blend series but the data is not shown here.

\section{Thermal Properties}

The compatibility of polymer blends can be investigated by their thermal and crystallization behaviors based on DSC measurements. The DSC results of pure components, uncompatibilized and compatibilized PA6/PPE blends are summarized in Table 4. Figure 8 shows the DSC heating scans of PA6, PPE, and the uncompatibilized PA6/PPE $=70 / 30,50 / 50$,

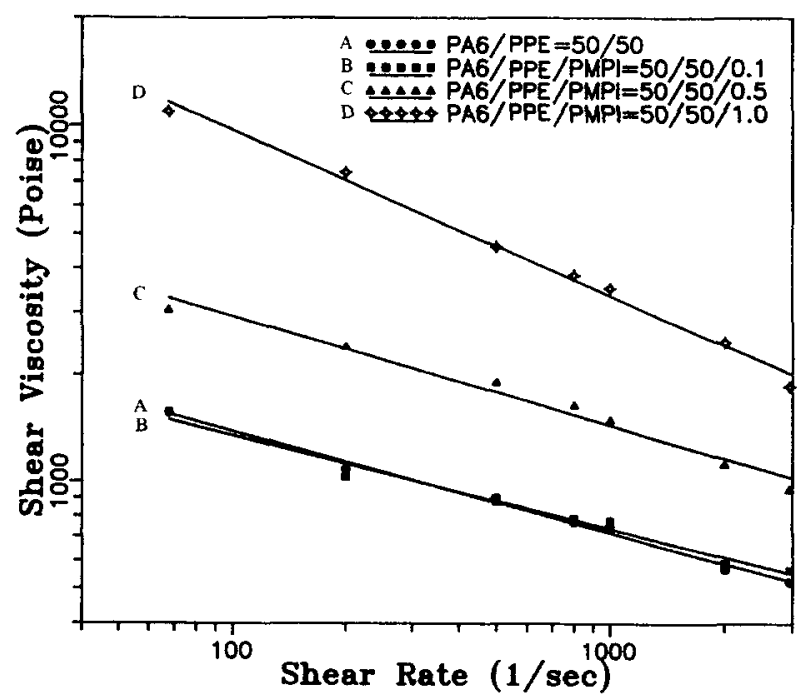

Fig. 7. Plots of shear viscosity versus shear rate for uncompatibilized and compatibilized PA6/PPE $=50 / 50$ blends. 
Table 4. Thermal Properties of the PA6/PPE Blends.

\begin{tabular}{|c|c|c|c|c|c|}
\hline Composition & $T_{g}\left({ }^{\circ} \mathrm{C}\right)$ & $\mathrm{T}_{\mathrm{m}, \mathrm{PA}}\left({ }^{\circ} \mathrm{C}\right)^{\mathrm{a}}$ & $T_{c, P A}\left({ }^{\circ} \mathrm{C}\right)^{b}$ & $\Delta H_{P A G}(J / g)^{c}$ & $X c(\%)^{d}$ \\
\hline $\begin{array}{l}\text { PA6 } \\
\text { PPE }\end{array}$ & 214 & 222 & 182 & 95.0 & 49.8 \\
\hline PA6/PPE $=70 / 30$ & & 220 & 199 & 70.2 & 52.6 \\
\hline $\mathrm{PA6} / \mathrm{PPE} / \mathrm{PMPI}=70 / 30 / 0.1$ & & 219 & 198 & 70.5 & 52.9 \\
\hline PA6/PPE/PMPI $=70 / 30 / 0.5$ & & 219 & 198 & 75.3 & 56.7 \\
\hline PA6/PPE/PMPI $=70 / 30 / 1.0$ & & 219 & 196 & 66.1 & 50.0 \\
\hline $\mathrm{PA} 6 / \mathrm{PPE}=50 / 50$ & & 219 & 197 & 47.6 & 49.9 \\
\hline PA6/PPE/PMPI $=50 / 50 / 0.1$ & & 219 & 197 & 48.7 & 51.2 \\
\hline PA6/PPE/PMPI $=50 / 50 / 0.5$ & & 219 & 196 & 46.9 & 49.5 \\
\hline PA6/PPE/PMPI $=50 / 50 / 1.0$ & & 218 & 193 & 42.0 & 44.5 \\
\hline $\mathrm{PA6} / \mathrm{PPE}=30 / 70$ & & 219 & 196 & 24.5 & 42.9 \\
\hline PA6/PPE/PMPI $=30 / 70 / 0.1$ & & 219 & 196 & 22.7 & 39.7 \\
\hline PA6/PPE/PMPI $=30 / 70 / 0.5$ & & 218 & 194 & 24.1 & 42.4 \\
\hline PA6/PPE/PMPI $=30 / 70 / 1.0$ & & 216 & 189 & 21.9 & 38.7 \\
\hline
\end{tabular}

a The melting temperature of PA6.

b The crystallization temperature of PA6.

${ }^{c}$ Heat of fusion of PA6 phase.

d Crystallinity of PA6 phase.

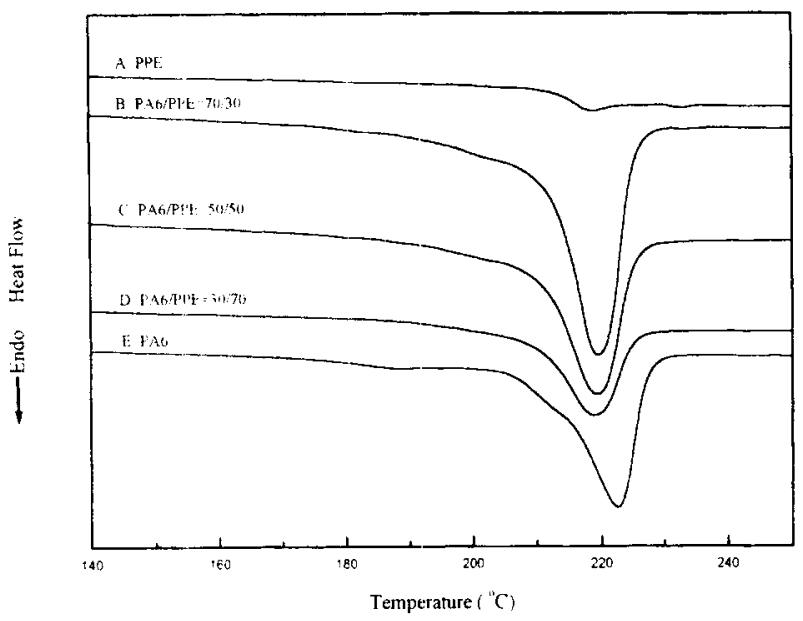

Fig. 8. DSC heating scans of PA6, PPE, and various uncompatibilized PA6/PPE blends.

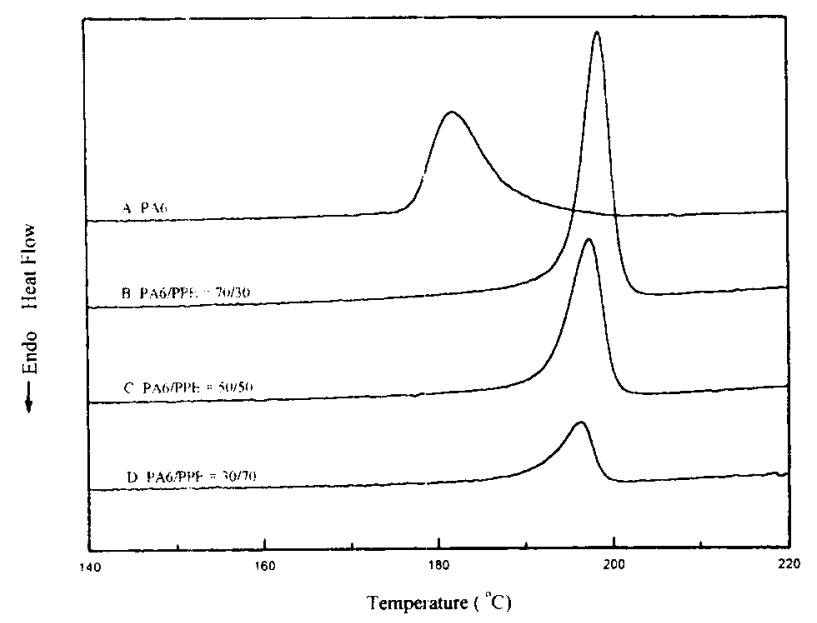

Fig. 9. DSC cooling scans of PA6, PPE, and various uncompatibilized PA6/PPE blends. and $70 / 30$ blends. The amorphous PPE shows a glass transition temperature $\left(T_{g}\right)$ at $214^{\circ} \mathrm{C}$ (Curve A, Fig. 8). PA6 is a semicrystalline polymer with a melting temperature (Tm) at $222^{\circ} \mathrm{C}$ (Curve E, Fig. 8). The glass transition of the PPE component in these uncompatibilized PA6/PPE blends cannot be detected because the melting peak of PA6 is overlapped with the glass transition of the PPE. The crystallinities of the PA6 component in these uncompatibilized binary blends are about the same as the virgin PA6 (Table 4). Crystallization temperatures $\left(T_{c s}\right)$ of the PA6 component (cooling scanning) in these uncompatibilized blends are substantially higher than that of the neat PA6 (Fig. 9 and Table 4). Peak widths of these uncompatibilized blends are substantially smaller than the neat PA6. The presence of PPE in these uncompatibilized blends is able to increase both crystallinity and crystallization rates of the PA6 component. Figure 10 shows

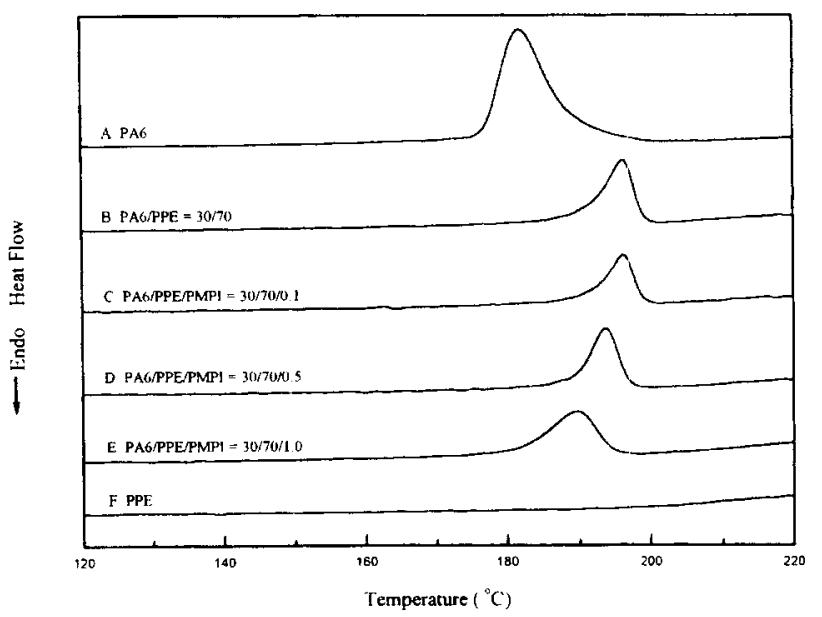

Fig. 10. DSC cooling scans of PA6, PPE, and various PA6/PPE $=30 / 70$ blends. 


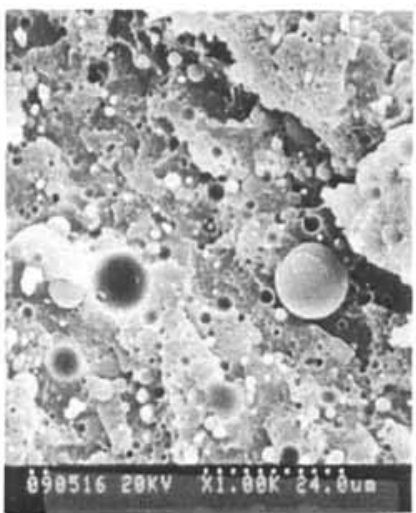

A: $\mathrm{PA6} / \mathrm{PPE}=70 / 30$

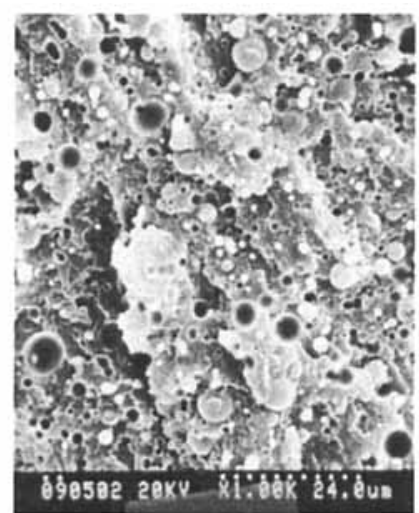

B: PA6/PPE/PMPI=70/30/0.1

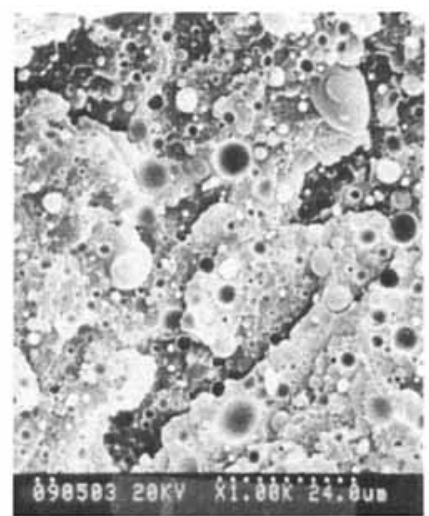

C: $\mathrm{PA6} / \mathrm{PPE} / \mathrm{PMPI}=70 / 30 / 0.5$

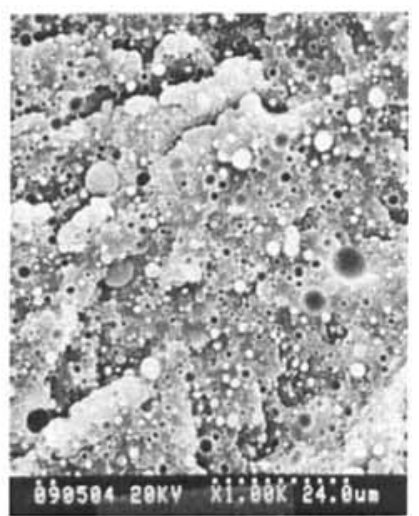

D: PA6/PPE/PMPI $=70 / 30 / 1.0$

Fig. 11. SEM micrographs of the uncompatibilized and compatibilized $P A 6 / P P E=70 / 30$ blends.

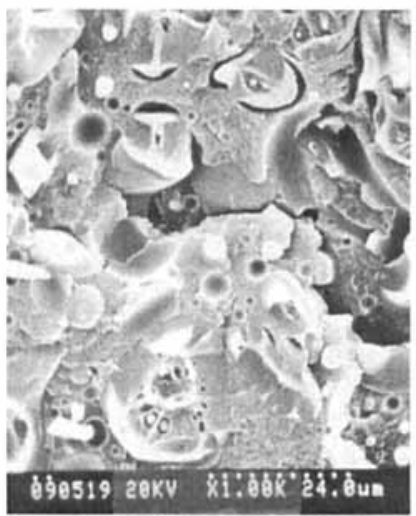

A: $\mathrm{PA} 6 / \mathrm{PPE}=50 / 50$

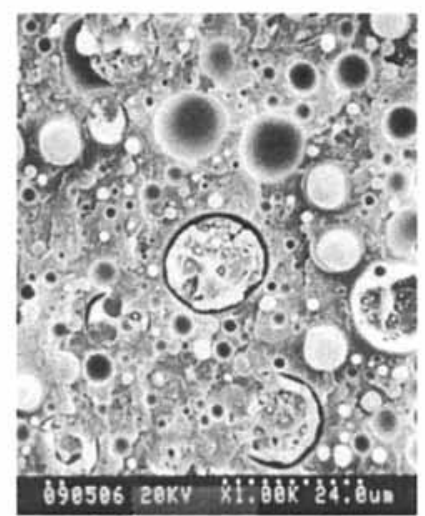

B: PA6/PPE/PMPI $=50 / 50 / 0.1$

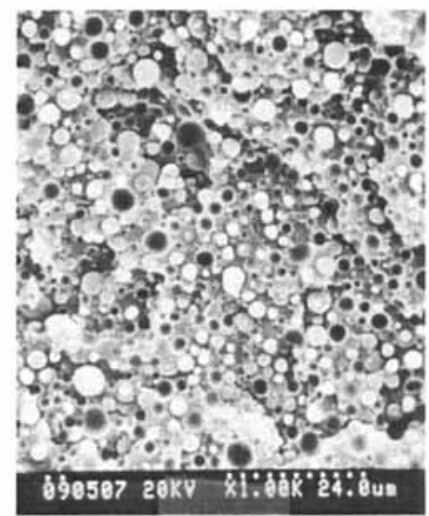

C: PA6/PPE/PMPI $=50 / 50 / 0.5$

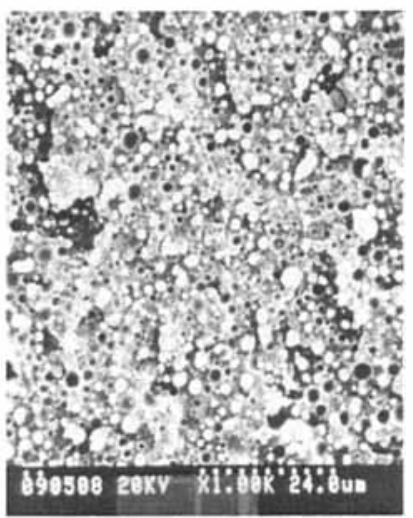

D: PA6/PPE/PMPI $=50 / 50 / 1.0$

Fig. 12. SEM micrographs of the uncompatibilized and compatibilized PA6/PPE $=50 / 50$ blends.

the cooling scans of PA6, PPE, uncompatibilized and various compatibilized $\mathrm{PA6} / \mathrm{PPE}=30 / 70$ blends. Again, the $T_{c s}$ of the PA6 component in these blends are all higher than that of the neat PA6. However, the observed $T c$ decreases with the increase of the compatibilizer quantity (Curves B to E, Fig. 10). General trend shows that more compatibilizer results in lower PA6 crystallinity (Table 4). The in situ-formed PA6-coPMPI-co-PPE copolymer tends to interfere the PA6 crystallization, especially in the vicinity of interface, and results in lower crystallinity than the uncompatibilized blend.

\section{Morphologies}

SEM photomicrography is the most convenient method to differentiate between the morphology of compatibilized and uncompatibilized blends. Melt blended immiscible polymer blends possess complicated phase morphologies depending on interfacial tension, viscosity ratio of blend constituents, volume fraction and processing conditions. The minor phase formation in blends is usually assumed that the size and the shape of the domains are the result of melt viscosity effects or viscoelasticity effects being balanced by interfacial tension $(40,41)$. The early stage of the dispersion process is an abrasion mechanism, and the final domain size of polyblends can be controlled by a dispersion-coalescence equilibrium (42).

Figure 11 shows the SEM micrographs of the uncompatibilized and compatibilized PA6/PPE $=70 / 30$ blend system. The general trend indicates that the dispersed PPE particle size decreases with the increase of the PMPI content. Figure 12 gives micrographs of the PA6/PPE $=50 / 50$ blend series where the PA6 is also the continuous phase. The uncompatibilized PA6/PPE $=50 / 50$ and the compatibilized PA6/PPE/PMPI $=50 / 50 / 0.1$ blends show a significant amount of PA6 occlusion as small particles within the irregular and large dispersed PPE domains (Figs. 12A and 12B). Figures $12 B$ to $12 D$ are the morphologies of the blends containing various amounts of PMPI compatibilizer, varying from 0.1 to $1.0 \mathrm{phr}$. The compatibilized blends give more regular and uniform spherical particles of the PPE phase than the uncompatibilized blend. The domain size decreases with the increase of compatibilizer quantity as would be expected from any efficiently compatibilized blend. The morphologies of PA6/PPE $=30 / 70$ blends, uncompatibilized and compatibilized, are given in Fig. 13. The uncompatibilized PA6/PPE $=30 / 70$ blend shows 


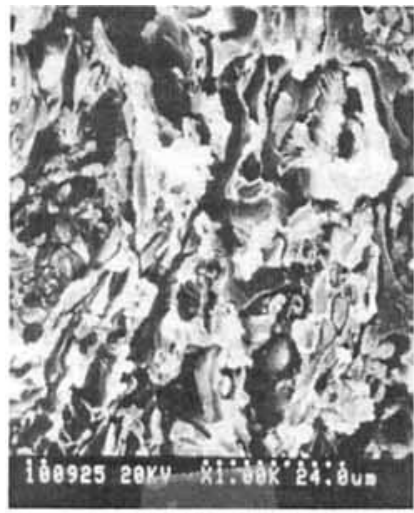

A: $\mathrm{PA} 6 / \mathrm{PPE}=30 / 70$

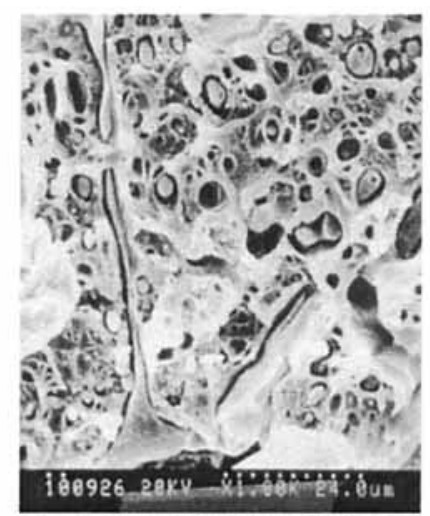

B: PA6/PPE/PMPI $=30 / 70 / 0.1$

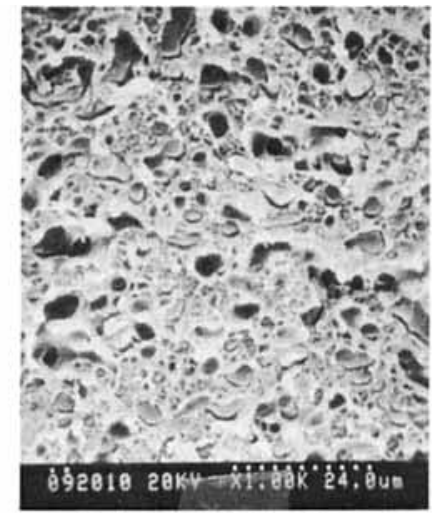

C: $\mathrm{PA} 6 / \mathrm{PPE} / \mathrm{PMPI}=30 / 70 / 0.5$

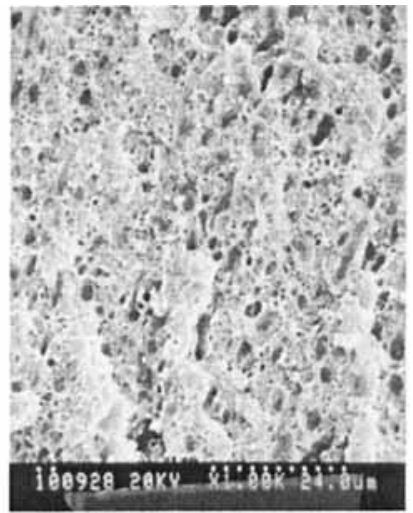

D: PA6/PPE/PMPI $=30 / 70 / 1.0$

Fig. 13. SEM micrographs of the uncompatibilized and compatibilized PA6/PPE $=30 / 70$ blends.

a nearly co-continuous phase structure. PA6 is the minor component in this blend but tends to become co-continuous because the viscosity of PA6 is significantly lower than that of PPE. The introduction of 0.1 phr PMPI to the PA6/PPE blend results in co-existence of spherical particles and elongated PA6 domains (Fig. 13B). The increase of the compatibilizer content has the tendency to shift the co-continuous structure of the uncompatibilized blend to a morphology with dispersed PA6 particles. The domain size of PA6 becomes finer with increasing amount of the compatibilizer.

\section{Mechanical Properties}

In general, a compatibilized polyblend has finer phase domain size, greater interfacial contact area, and higher interfacial adhesion than the corresponding uncompatibilized blend that is critical to stress transfer between phases. All the measured mechanical properties of PA6/PPE blends including unnotched Izod impact strengths and tensile properties are listed in Table 5 and Figs. 14 to 16. Since both PA6 and PPE matrices are notched sensitive materials, all the PA6/PPE blends, uncompatibilized and compatibilized, are notch brittle with almost the same low notched impact strength. Unnotched impact strength is more appropriate to differentiate the toughness change of the notch sensitive blends through compatibilization.
Figure 14 shows the effect of PMPI content on the unnotched impact strength. The unnotched impact strength at room temperature of the PA6/PPE blend increases with the increase of PMPI compatibilizer quantity. The improvement of impact strength is dramatic, especially for PPE-rich blends, considering only $1.0 \mathrm{phr}$ or less PMPI compatibilizer is employed. For $\mathrm{PA6} / \mathrm{PPE}=70 / 30$ and $50 / 50$ blend series, the impact strength increases more gradually with increasing the compatibilizer quantity. The effect of the PMPI compatibilizer on impact strength of the PA6/PPE $=30 / 70$ blend series is very striking; the impact strength of the blend containing 1.0 phr PMPI shows about 10 times greater than the corresponding uncompatibilized counterpart. Figure 15 demonstrates the effect of compatibilizer content in PA6/PPE blend on the resultant tensile strength. The improvement of the tensile strength is also very drastic through compatibilization. Since the reaction between PMPI with PA6 is faster than with PPE, addition of more PMPI compatibilizer is essential to produce critical amount of PA6-co-PMPIco-PPE copolymer at the interface.

The critical strain energy release rate $(G c)$ derived from the basic fracture mechanics in terms of energy absorbed by the conventional Izod impact test has been previously developed (38). The energy absorbed by the impact at fracture rather than at the maximum

Table 5. Summarized Mechanical Properties of PA6/PPE/PMPI Blends.

\begin{tabular}{|c|c|c|c|c|}
\hline Composition & $\begin{array}{l}\text { Unnotched Izod } \\
\text { Impact (J/M) }\end{array}$ & $\begin{array}{c}\text { Tensile Strength } \\
\text { (MPa) }\end{array}$ & $\begin{array}{l}\text { Tensile Elongation } \\
(\%)\end{array}$ & $\begin{array}{c}G_{c} \times 10^{-3} \\
\left(\mathrm{~J} / \mathrm{m}^{2}\right)\end{array}$ \\
\hline $\begin{array}{l}\mathrm{PA6} / \mathrm{PPE}=70 / 30 \\
\mathrm{PA6} / \mathrm{PPE} / \mathrm{PMPI}=70 / 30 / 0.1 \\
\mathrm{PA6} / \mathrm{PPE} / \mathrm{PMPI}=70 / 30 / 0.5 \\
\mathrm{PA6} / \mathrm{PPE} / \mathrm{PMPI}=70 / 30 / 1.0 \\
\mathrm{PA6} / \mathrm{PPE}=50 / 50 \\
\mathrm{PA6} / \mathrm{PPE} / \mathrm{PMPI}=50 / 50 / 0.1 \\
\mathrm{PA6} / \mathrm{PPE} / \mathrm{PMPI}=50 / 50 / 0.5 \\
\mathrm{PA6} / \mathrm{PPE} / \mathrm{PMPI}=50 / 50 / 1.0 \\
\mathrm{PA6} / \mathrm{PPE}=30 / 70 \\
\mathrm{PA6} / \mathrm{PPE} / \mathrm{PMPI}=30 / 70 / 0.1 \\
\mathrm{PA6} / \mathrm{PPE} / \mathrm{PMPI}=30 / 70 / 0.5 \\
\mathrm{PA6} / \mathrm{PPE} / \mathrm{PMPI}=30 / 70 / 1.0\end{array}$ & $\begin{array}{r}123 \\
116 \\
139 \\
370 \\
192 \\
152 \\
314 \\
418 \\
118 \\
152 \\
487 \\
1009\end{array}$ & $\begin{array}{l}35.6 \\
36.6 \\
39.0 \\
45.1 \\
40.1 \\
43.1 \\
45.3 \\
51.3 \\
34.2 \\
37.0 \\
53.6 \\
56.8\end{array}$ & $\begin{array}{l}4.0 \\
2.7 \\
2.6 \\
3.5 \\
5.5 \\
3.1 \\
3.4 \\
7.7 \\
3.8 \\
3.4 \\
5.6 \\
7.4\end{array}$ & $\begin{array}{l}3.75 \\
3.73 \\
3.76 \\
6.17\end{array}$ \\
\hline
\end{tabular}




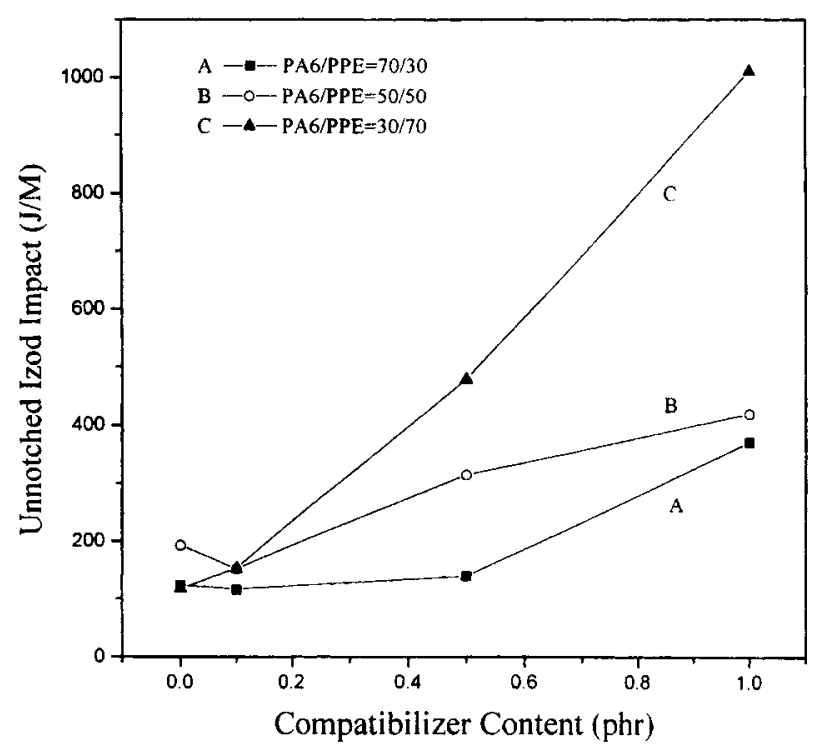

Fig. 14. Effect of compatibilizer quantity on the impact strength of the PA6/PPE blends.

load is assumed to deform in a total elastic manner. In addition, the observed energy is also a function of crack length and the geometry. We can obtain the Gc of the blends by the following equation derived by Plati and Williams (38).

$$
W=G c \times B \times D \times \Phi
$$

The $W$ is the notched impact energy, $B$ is the specimen thickness. $D$ is the notched width, and $\Phi$ is the geometrical factor. Figure 16 illustrates the typical plots of notched impact strength versus $B D \Phi$ to determine the Gcs from the slopes of these regression lines.

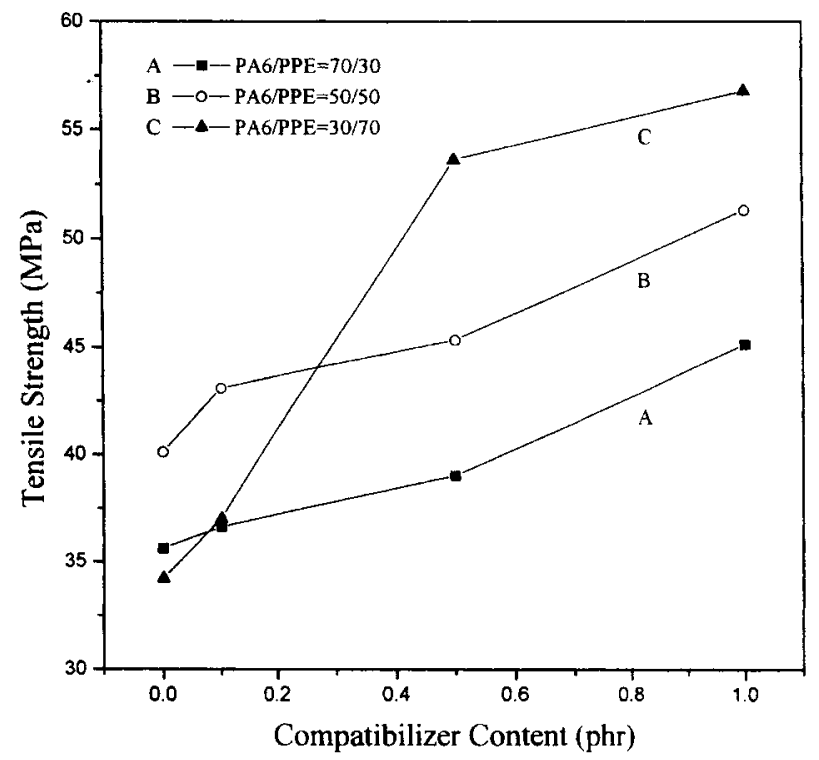

Fig. 15. Effect of compatibilizer quantity on the tensile strength of the PA6/PPE blends.
Gcs of the PA6/PPE $=30 / 70$ blend series are summarized in Fig. 16 and Table 5. The trend of Ge versus PMPI compatibilizer content of PA6/PPE $=70 / 30$ blends is similar to that of the unnotched impact strength. The Gc increases about double for the compatibilized blend relative to the uncompatibilized blend by the addition of $1.0 \mathrm{phr}$ PMPI compatibilizer (Fig. 16). For those compatibilized blends containing less than $0.5 \mathrm{phr}$, their $G c$ values are nearly identical to the uncompatibilized blend.

The molecular weight increase by chain extension and the interfacial adhesion enhancement by the PA6-co-PMPI-co-PPE copolymer anchoring along the interface are both responsible for the observed mechanical property improvements.

\section{CONCLUSION}

A selected reactive coupling agent can be used to compatibilize certain incompatible blends provided both of the blend components possess the necessary functional groups. This study has focused on the compatibilizing effects of an oligomeric isocyanate PMPI as a coupler type reactive compatibilizer for the incompatible PA6/PPE blends. Fraction of this PMPI coupler is able to react with both PA6 and PPE simultaneously at the interface to form the desired PA-coPMPI-co-PPE mixed copolymer. This in situ-formed copolymer tends to anchor along the interface to function as an efficient compatibilizer by reducing interfacial tension and enhancing the interfacial adhesion. Significant mechanical property improvement can be achieved by the addition of a small amount of PMPI coupler in PA6/PPE blends. The presence of PPE in PA6/PPE blends tends to increase PA6 crystallinity and crystallization rates.

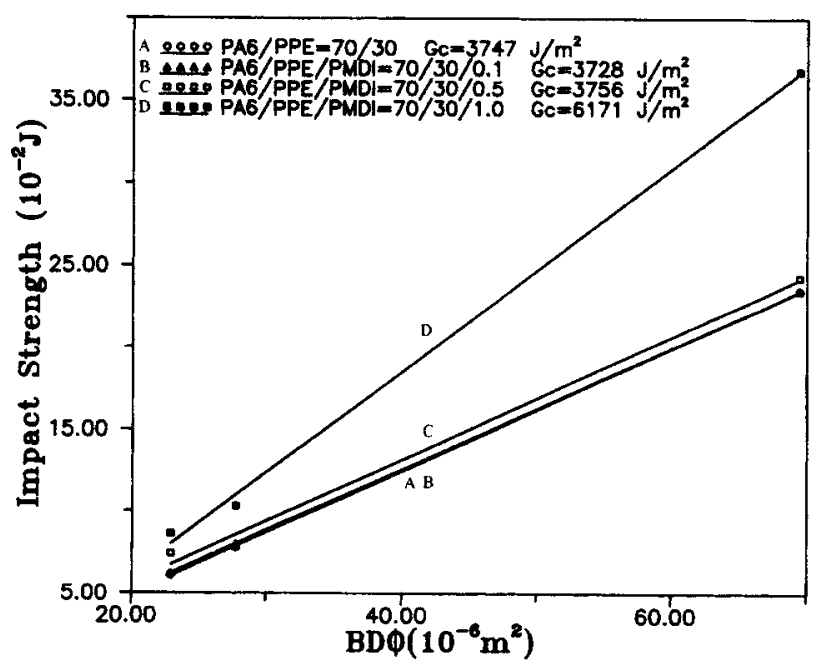

Fig. 16. Plots of impact strength versus $B D \Phi$ of various PA6/ $P P E=70 / 30$ blends. 


\section{ACKNOWLEDGENT}

The authors are grateful to the National Science Council, Republic of China, for the financial support through contract NSC85-2216-E009-001. Also the authors want to thank the Elastogran Headway Urethanes Co., Ltd., of Taiwan to supply PMPI.

\section{REFERENCES}

1. L. Mascia and M. Xanthos, Adv. Polym. Technol, 11, 237 (1992).

2. M. Xanthos and S. S. Dagli, Polym. Eng. Sci, 31, 929 (1991).

3. F. C. Chang, "Compatibilized Thermoplastics Blends," in Handbook of Thermoplastics, Ch. 21, 491, O. Olabisi, ed., Marcel Dekker Publishers, New York (1997).

4. M. K. Akkapeddi, B. V. Buskirk, and G. J. Dege, SPE ANTEC, 40, 1509 (1994).

5. J. R. Campbell, S. Y. Hobbs, T. J. Shea, and V. H. Watkins, Polym. Eng. Sci, 30, 1056 (1990).

6. D. Ghidoni, E. Bencini, and R. J. Nocci, Mater. Sci, 31, 95 (1996)

7. S. B. Brown, Polym. Prep., 33 (2), 598 (1992).

8. C. Koning and L. V. D. Vondervoort, SPE ANTEC, $\mathbf{3 8}$, 1435 (1992).

9. S. Y. Hobbs, M. E. J. Dekkers, and V. H. Watkins, J. Mater. Sci. 24, 2025 (1989).

10. S. Y. Hobbs and M. E. J. Dekkers, J. Mater. Sci, 24, $1316(1989)$.

11. K. Suzuki and S. Ono, Jpn Pat. 60-155259 (1985).

12. H. Kasahara, K. Fukuda, and H. Suzuki, Jpn Pat. 5736150 (1982).

13. I. Yamahsita, H. Kasahara, and K. Fukuda, Jpn Pat. $57-165448$ (1982).

14. W. H. Jo and H. C. Kim, Polym. Bull, 27, 465 (1992).

15. H. C. Kim and W. H. Jo, Polym. Eng. Sci., 35, 648 (1995).

16. C. R. Chiang and F. C. Chang, Polymer, 38, 4807 (1997).

17. C. R. Chiang and F. C. Chang, J. Polym. Sci, Polym. Phys. Edn., to appear.

18. C. R. Chiang and F. C. Chang, J. AppL Polym Sci, 61, 2411 (1996)

19. S. B. Brown, in Reactive Extrusion, Ch. 4, M. Xanthos, ed., Hanser Publishers, New York (1992).
20. W. B. Liu, W. F. Kuo, C. R. Chiang, and F. C. Chang, Eur. Polym. J. 32, 91 (1996).

21. A. Tzur, M. Narkis, A. Siegmann, M. Seadan, and M. Lambla, Polym. Network Blends, 5, 107 (1995).

22. J. W. Teh and A. Rudin, Polym. Eng. Sci., 32, 1678 (1992).

23. Y. Thomas, J. P. Parisi, B. Bontevin, D. Beziers, and E. Chataigner, Compos. Sci. Technol, 52, 299 (1994).

24. T. Koseki, T. Sakamoto, M. Ito, S. Maeda, and T. Heiuchi, Jpn Pat. 62-124120 (1987).

25. P. Pernice, C. Berto, A. Moro, and R. Pippa, US. Pat., 5,210,125 (1993)

26. C. Koning, A. VanGeenen, Z. Roerdink, R. M. Faty, and P. Teyssie, Eur. Pat., A-357.112 (1989).

27. Jpn. Pat. 5-194698 (1993).

28. Jpn. Pat. 5-194700 (1993).

29. Jpn. Pat. 5-78578 (1993).

30. H. C. Chin, K. C. Chiou, and F. C. Chang, J. Appl. Polym. Sci., 60, 2503 (1996).

31. C. C. Huang and F. C. Chang, Polymer, 38, 2135, 4287 (1997).

32. D. W. Lo, C. R. Chiang, and F. C. Chang, J. AppL Polym. Sci, 65, 739 (1997).

33. C. R. Chiang and F. C. Chang, J. Polym. Res., 4, 91 (1997).

34. W. J. Macknight and R. W. Lenz, Polym. Eng. Sci, 25 , 1124 (1985).

35. I. Park, J. W. Barlow, and D. R. Paul, J. Polym. Sci, Polym. Phys., 30, 1021 (1992).

36. W. H. Jo, C. D. Park, and M. S. Lee, Polymer, 37, 1709 (1996).

37. D. V. Howe and M. D. Wolkowicz, Polym. Eng. Sci, 27, 1582 (1987).

38. E. Plati and J. G. Williams, Polym. Eng. Sci, 15, 470 (1975).

39. D. D. White and S. A. Nye, Macromolecules, 23, 1318 (1990).

40. A. P. Plochocki, S. S. Dagli and R. D. Andrews, Polym. Eng. Sci, 30, 741 (1990).

41. I. Fortelny and A. Zivny, Polym. Eng. Sci, 35, 1872 (1995).

42. U. Sundararaj and C. W. Macosko, Macromolecules, 28, 2647 (1995).

Received Jan. 6, 1997 Revised June 1997 